\title{
Modeling the vertical distribution of oyster larvae in response to environmental conditions
}

\author{
Margaret M. Dekshenieks ${ }^{1, *}$, Eileen E. Hofmann ${ }^{1}$, John M. Klinck ${ }^{1}$, Eric N. Powell ${ }^{2}$ \\ ${ }^{1}$ Center for Coastal Physical Oceanography, Old Dominion University, Norfolk, Virginia 23529, USA \\ ${ }^{2}$ Haskin Shellfish Research Laboratory, Rutgers University, Port Norris, New Jersey 08349, USA
}

\begin{abstract}
A size-structured, time and vertically-dependent model was used to investigate the effects of water column structure on the distribution of larvae of the oyster Crassostrea virginica. Formulations used to model larval growth and behavior are based upon laboratory studies. Simulated vertical larval distributions obtained for conditions representative of a well-mixed, partially stratified and strongly stratified water column illustrate the effect that salinity and temperature gradients have on moderating larval swimming and hence on larvae vertical location. For well-mixed conditions, smaller larvae are dispersed throughout most of the water column. For strongly stratified conditions, the smaller-sized larvae cluster within the region of strong salinity change. Intermediate-sized larvae cluster within or directly below the region of strong salinity change. The oldest larvae are found near the bottom for all salinity conditions since their location is determined primarily by sinking rate. Additional simulations show that diurnal salinity changes interact with larval behavioral responses to create patchy larval distributions. Finally, simulations show that the inclusion of an upwelling or downwelling velocity can overwhelm the behavioral responses of smaller larvae and result in much different vertical distributıons. The simulated vertical larval distributions show that changes in larval migratory behavior which are brought about by changes in the vertical salınity gradient can significantly alter larval distribution patterns. These, when combined with horizontal advective flows, have important implications for larval dispersal.
\end{abstract}

KEY WORDS: Larval behavior - Oyster larvae Numerical modeling

\section{INTRODUCTION}

The role of passive versus active regulation in the distribution and retention of planktonic larvae in estuarine systems is a subject that has been long discussed. On one side is the contention that larvae are simply passive particles whose distribution is determined by the prevailing current system (e.g. Korringa 1952, Verwey 1966). At the other extreme is the belief that larvae, through behavioral responses that have developed over evolutionary time in response to particular environmental forcings, determine their own fate (Wood \& Hargis 1971). Attempts have been made to measure the processes that control larval distributions in estuarine systems (Carriker 1951, Wood \& Hargis 1971). However, as shown by these studies, assessing

\footnotetext{
- Present address: Graduate School of Oceanography, University of Rhode Island, South Ferry Road, Narragansett, Rhode Island 02882, USA. E-mail: deks@holo.gso.uri.edu
}

the extent to which circulation and/or behavioral processes control larval distribution and retention is difficult. The likely explanation for this is that observed larval patterns result from a combination of the 2 effects (Boicourt 1982).

Mathematical models that include biological as well as circulation processes provide an approach for investigating and separating environmental and biological factors which control larval distribution. A number of models have been constructed to investigate larval retention, transport pathways and distribution in estuarine and neritic environments [see Hofmann \& Lascara (in press) for a review]. One approach taken is to treat larvae as simple passive drifters, with the final location being determined totally by the circulation. The simulated larval distributions thus obtained usually do not comnare well with observed distributions and the need for inclusion of biological effects, mainly behavior, is the primary conclusion from these models. Larval transport models that include biological compo- 
nents typically use a prescribed vertical migration strategy for all (Rothlisberg et al. 1983) or part (Wroblewski 1982) of an animal's life history or a vertical motion (sinking or swimming) that is determined by animal development and growth (Hofmann et al. 1992). The simulated larval distributions from these models tend to compare better with observed distributions, and sensitivity studies show that behavior is an important factor in determining larval transport and/or retention.

Of the many larval species found in estuarine systems, much effort has been expended on attempting to understand the factors that regulate the distribution of larvae of the Eastern oyster Crassostrea virginica. Under optimal conditions, these larvae remain planktonic for 14 to 25 d (Dekshenieks et al. 1993), after which time they settle. It has been suggested that older larvae of $C$. virginica may counteract the dispersal effects of the local estuarine circulation by swimming upward on the flood tide in response to increases in salinity and sinking downward on the ebb tide in response to decreases in salinity (Kunkle 1957. Crisp 1976). The net effect of this behavior would be up-estuary transport of the older larval stages. Moreover, field studies have shown a strong correlation between salinity and oyster larval position that cannot be explained by passive transport (Wood \& Hargis 1971).

This study uses the approach of mathematical modeling to investigate the effects of circulation and biological processes, such as growth, swimming ability and size-dependent vertical migratory behavior, in regulating the vertical distribution of Crassostrea virginica larvae. Larval growth, from egg to settlement, is modeled as a function of ambient temperature, salinity, turbidity and food as described in Dekshenieks et al. (1993). Larval swimming ability is parameterized using observed dependencies on temperature, salinity and larval size. Thus, ambient environmental conditions can potentially affect larval position. Vertical advection and diffusion are included as prescribed fields that are representative of conditions encountered in Chesapeake Bay, USA.

The environmental conditions of temperature, salinity and food supply that are input to the model are representative of Chesapeake Bay at different times of the year. Thus, the effects on vertical larval distribution of changes in the physical environment, as vertical stratification in temperature and salinity develops in the Bay from spring to summer, can be examined. The model provides simulations of the vertical and time-dependent distributions of a cohort of individuals from spawn to settlement. The simulations are analogous to following a cohort of individuals over time and mapping their vertical distribution. In this sense, the simulations are representative of what would be obtained from Lagrangian sampling, if it were possible to track a larval cohort over its planktonic lifetime.

The following section provides a description of the vertical and time-dependent model and the parameterizations that were used in the model. Following this a series of simulations that consider homogeneous to strongly stratified conditions are presented. The final section provides a discussion and summary. The results of this study provide insight into the processes that regulate the vertical distribution of oyster larvae. However, they are relevant to any species that has a planktonic larval form.

\section{MODEL}

The vertical- $(z)$ and time-dependent $(t)$ distribution of an oyster larvae of a given size, $L_{1}$, is assumed to be governed by:

$$
\frac{\partial L_{1}}{\partial t}+W_{T} \frac{\partial L_{i}}{\partial z}+K_{z} \frac{\partial^{2} L_{i}}{\partial z^{2}}=\left(\text { growth }_{1-1}\right)-\left(\text { loss }_{i+1}\right)
$$

The first term on the left side of Eq. (1) represents the time rate of change of the number of larvae in a particular size class, $i$. The effects of vertical advection and vertical diffusion on larval distribution are represented by the next 2 terms, respectively. The coefficient, $K_{n}$, determines the rate of vertical diffusion and may be specified as either a constant or variable value. The terms on the right side of Eq. (1) represent the biological processes that determine the rate of transfer to the next largest size. The number of larvae of a particular size changes by growth of new individuals from the previous size $\left(\right.$ growth $\left._{j-1}\right)$ and the loss of individuals to the next largest size $\left(\operatorname{loss}_{1+1}\right)$. The formulations used to describe larval growth are described in the following section.

The total vertical advective velocity, $W_{T}$, is composed of contributions from the vertical circulation, $W_{a}$ and the size-dependent biologically produced vertical movement (sinking or swimming), $W_{b,}$ as:

$$
W_{T}=W_{a}+W_{b i}
$$

The value of $W_{a}$ is specified as a constant velocity or as functions that vary in space and time. The value of $W_{b i}$ is determined from relationships that depend on ambient temperature and salinity and larval size, as described in the following section.

\section{Larval growth}

The larval growth model, which determines the rate of transfer between size classes, was parameterized based on laboratory observations that give the change 
Table 1. Summary of the oyster larvae growth and development model given in Dekshenieks et al. (1993). The governing equation is: $\mathrm{d} S / \mathrm{d} t=$ growth(food, size) $\times$ ts factor $\times$ turbef. The terms in the governing equations are defined and the characteristics of each are given. Data sources on which the parameterizations for the larval growth process are based are given. The figure in Dekshenieks et al. (1993) that shows the relationships used in the larval growth model is indicated for each term

\begin{tabular}{|c|c|c|c|}
\hline Term & Definitions and characterıstics & Data sources & Fig. no. \\
\hline $\mathrm{d} S / \mathrm{d} t$ & $\begin{array}{l}\text { Time rate of change of larval size (S) expressed } \\
\text { in } \mu \mathrm{m}\end{array}$ & Dekshenieks et al. (1993) & 9 \\
\hline growth(food, size) & $\begin{array}{l}\text { Low growth rates at low food for all sizes, } \\
\text { maximum growth occurs at } 3.0 \mathrm{mg} \mathrm{AFDW}^{-1} \text {, } \\
\text { for larvae } 105-135 \mu \mathrm{m}\end{array}$ & Rhodes \& Landers (1973) & 2 \\
\hline ts factor & $\begin{array}{l}\text { Low growth at low temperatures and salinities, } \\
\text { increased growth with increased temperature, } \\
\text { increased growth at salinities of } 17.5 \text { to } 25 \mathrm{ppt}\end{array}$ & $\begin{array}{l}\text { Davis (1958) } \\
\text { Davis \& Calabrese (1964) }\end{array}$ & 3 \\
\hline turbef & $\begin{array}{l}\text { "Turbidity effect which is defined as: } \\
\text { turbef }=m \times \text { turb }+c\left(\text { for turbidity }<0.1 \mathrm{~g} \mathrm{l}^{-1}\right) \\
\left.\text { turbef }=b e^{\text {Aurb } \ldots \text { surbe) }} \text { (for turbidity }>0.1 \mathrm{~g} \mathrm{l}^{-1}\right)\end{array}$ & $\begin{array}{l}\text { Davis (1960) } \\
\text { Huntington \& Miller (1989) }\end{array}$ & 4 \\
\hline
\end{tabular}

in larval size as a function of food supply, temperature and salinity, and turbidity (Table 1). The larval growth model was verified with observed growth rates and has been used to investigate differences in larval growth rate and planktonic time resulting from environmental conditions in a range of bays and estuaries (Dekshenieks et al. 1993).

The simulated time-dependent growth of oyster larvae clearly showed the importance of temperature and food concentration in determining larval planktonic time (Dekshenieks et al. 1993). For favorable salinity and food conditions, a decrease in temperature from 30 to $18^{\circ} \mathrm{C}$ can double the larval planktonic time (Fig. 1). Decreases in food supply result in even longer planktonic times (Fig. 1). The range of salinity and turbidity values typically encountered in most estuarine systems has less of an effect on larval growth rate and hence planktonic time. Detailed discussions of the larval growth model and the results obtained from it are given in Dekshenieks et al. (1993).

\section{Swimming and vertical migration}

Swimming speeds of bivalve veliger larvae are slow relative to horizontal current velocities and thus these larvae are usually regarded as passive particles in the horizontal plane (Mann 1986). Vertical current speeds however are slow relative to the alternating swimming and sinking behavior of these larvae. Hence, in most circumstances these larvae can undergo directed motion in the vertical.

As oyster larvae grow, their swimming speeds increase. However, as the larva produces shell it also

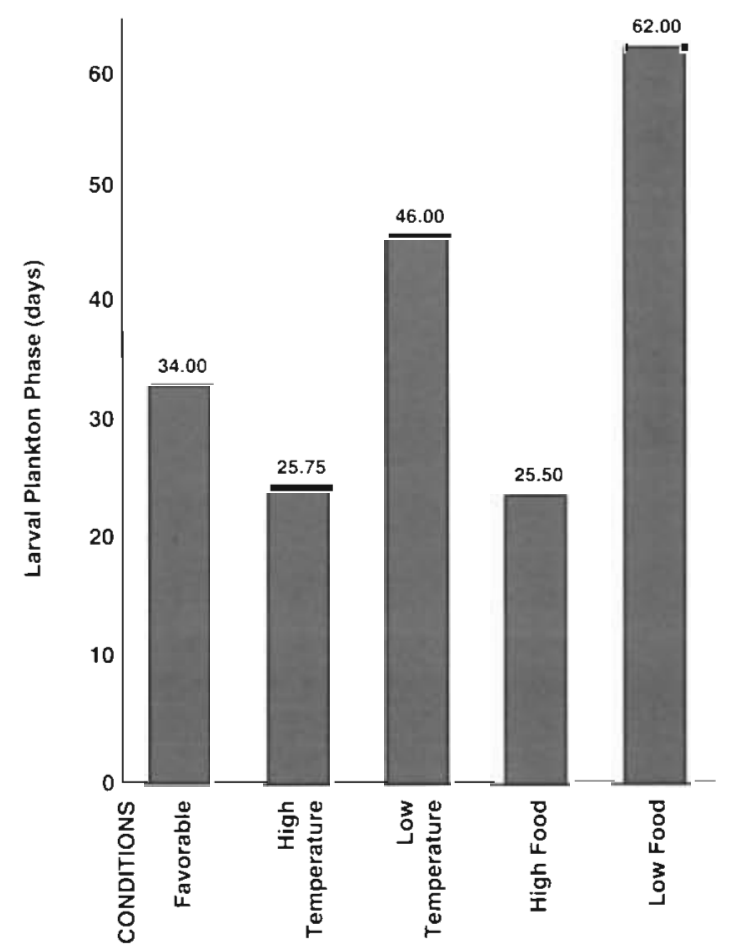

Fig. 1. Crassostrea virginica. Summary of total larval planktonic time in days obtained from the time-dependent larval growth model described by Dekshenieks et al. (1993) for different environmental conditions. Favorable conditions are $24^{\circ} \mathrm{C}, 25$ (ppt), and a food concentration of $2.0 \mathrm{mg} \mathrm{AFDW} \mathrm{l}^{-1}$ Temperature effects on larval planktonic time are illustrated by the high $\left(30^{\circ} \mathrm{C}\right)$ and low $\left(18^{\circ} \mathrm{C}\right)$ temperature simulations. Salinity and food conditions were taken to be favorable. Variations in planktonic time due to tood eftects are shown by simulations that use high ( $3.0 \mathrm{mg} \mathrm{AFDW} \mathrm{l}^{-1}$ ) and low $(1.0 \mathrm{mg}$ AFDW $1^{-1}$ ) food concentrations. Salinity and temperature values for these simulations were favorable 
increases in mass and density, thus increasing its sinking speed (Galtsoff 1964). This produces a continuously changing balance between larval swimming and sinking rates as the larvae grow, which ultimately results in a near-bottom position for the larvae ready for settlement (Baker 1991). Additionally, oyster larvae appear to undergo a directed vertical migration in response to changes in salinity (Nelson 1954, Wood \& Hargis 1971). An increase in salinity results in larvae becoming more active, and swimming a greater amount of the time. Salinity decreases are associated with decreasing larval activity, a reduction in swimming and thus downward (sinking) motion. These observed behaviors are included in the model as described below.

\section{Swimming rate}

Laboratory observations show that the swimming ability of oyster larvae depends upon temperature and larval size. In general, warmer temperatures and larger sizes result in higher swimming rates. Hidu \& Haskin (1978) and McCarthy (1989) present measurements of swimming rate for straight hinge $(75 \mu \mathrm{m})$. early umboned $(130 \mu \mathrm{m})$, late umboned $(270 \mu \mathrm{m})$, and mature $(300 \mu \mathrm{m})$ oyster larvae at 15,20 and $25^{\circ} \mathrm{C}$. These data were linearly interpolated to obtain larval swimming rates at intermediate temperatures and sizes. Swimming rates for larval sizes between 55 and $75 \mu \mathrm{m}$ were obtained by linear interpolation of the measured rate at $75 \mu \mathrm{m}$ and a zero swimming rate for eggs at $55 \mu \mathrm{m}$. Swimming rates for larvae at temperatures between 15 and $12^{\circ} \mathrm{C}$ were obtained by linear interpolation of the measured rate at $15^{\circ} \mathrm{C}$ and a zero swimming rate at $12^{\circ} \mathrm{C}$. Larvae can settle at a temper-

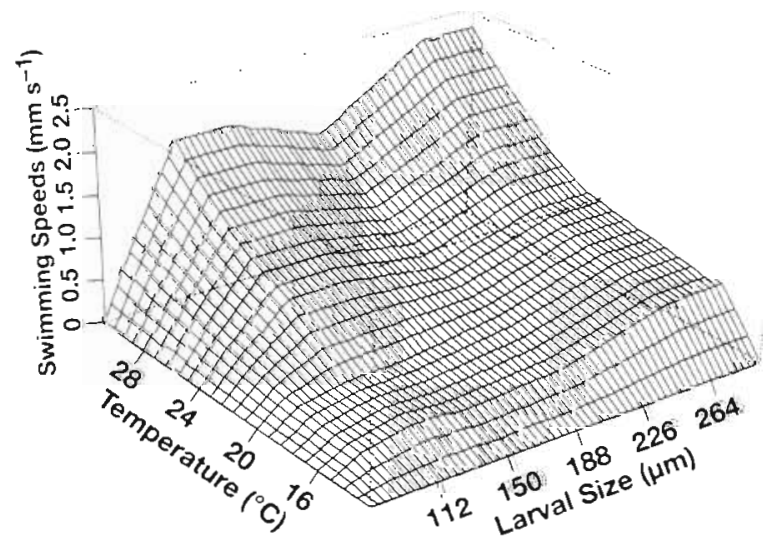

Fig. 2. Crassostrea virginica. Larval swimming speed in mm $\mathrm{s}^{-1}$ as a function of larval size and temperature. Swimming speed is denved from data given in Hidu \& Haskin (1978) and McCarthy (1989) ature as low as $12^{\circ} \mathrm{C}$ (Davis \& Calabrese 1964), and this minimum temperature was assumed to be the point at which swimming ceased. Swimming rates for larvae at temperatures above $25^{\circ} \mathrm{C}$ were obtained by applying a $Q_{10}$ value of 2 to the values at $25^{\circ} \mathrm{C}$ (Davis \& Calabrese 1964).

The larval swimming rates thus obtained (Fig. 2) increase rapidly at all temperatures until the larvae reach $115 \mu \mathrm{m}$, and then plateau for intermediate-sized larvae. Larval swimming rate again increases for larvae larger than $225 \mu \mathrm{m}$.

In laboratory experiments, Mann \& Rainer (1990) demonstrated that oyster larvae have a high tolerance to short-term hypoxic stress. Oyster larvae do not significantly cease swimming activity until exposed to exceedingly low oxygen levels. Therefore, the effect of lowered oxygen content on swimming speed was not included in the model.

\section{Sinking rate}

As oyster larvae mature, they develop a thin shell, and sink as a result of the increased mass. Laboratory studies have shown that larval sinking rate increases with increasing larval size. From measurements given in Hidu \& Haskin (1978), larval sinking rate, as a function of size, can be described as:

$$
S R=2.665 \mathrm{e}^{00058(S Z-220)}
$$

where $S R$ is larval sinking rate in $\mathrm{mm} \mathrm{s}^{-1}$ and $S Z$ is larval size in $\mu \mathrm{m}$. The relationship results in a sinking rate of $1 \mathrm{~mm} \mathrm{~s}^{-1}$ for small larvae and sinking rates up to $5 \mathrm{~mm} \mathrm{~s}^{-1}$ for larvae near settlement size (Fig. 3). Larval sinking rate does not vary significantly with salinity (Hidu \& Haskin 1978).

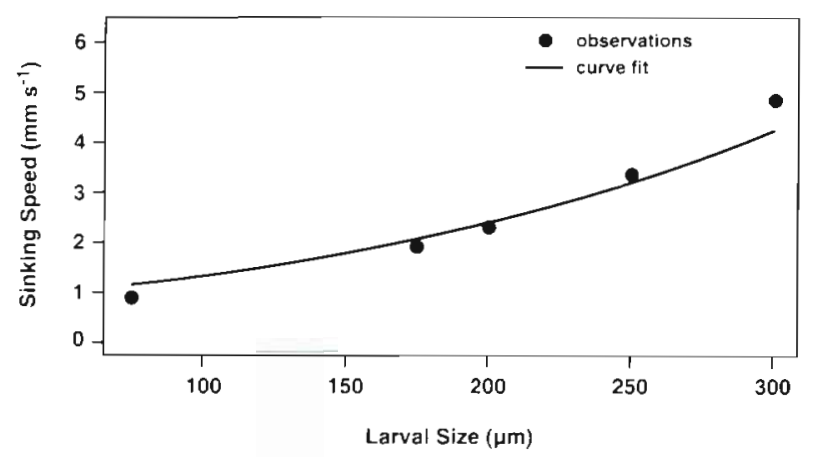

Fig. 3. Crassostrea virginica. Larval sinking speed in $\mathrm{mm} \mathrm{s}^{-1}$ as function of larval size. ( Sinking rates obtained from laboratory experiments (Hidu \& Haskin 1978). Solid line represents the curve fit to these data which is used in the model (Eq. 3) 
Fig. 4. Crassostrea virginica. Percent time spent swimming calculated from Eqs. (4) $\&(5)$ for a diurnally varying salinity. Associated salinity gradient is also shown

Percent time swimming

Observations (Haskin 1964, Hidu \& Haskin 1978) show that oyster larvae do not swim continuously, but rather undergo periods of upward motion that are interspersed with periods of rest. More recently Kennedy \& Van Heukelem (1986) suggested that oyster larvae vary the percent time spent swimming in response to the cumulative change (i.e. gradient) in salinity. Therefore, the parameterization of larval swimming behavior was modified to allow for variations in the percentage of time that larvae swim.

Haskin (1964) undertook a laboratory study to establish that varying salinity stimulates increased or decreased activity of oyster larvae. Two separate experiments were performed, both of which showed close correlations between salinity change and larval activity (Haskin 1964: Figs. 3 \& 4). These data were used to generate relationships between the percent active larvae during increasing and decreasing salinities and the cumulative increase and cumulative decrease in salinities, respectively. The resulting correlations between the percent time larvae swim and the cumulative salinity change $(\Delta S)$, in ppt time $e^{-1}$, were determined to be:

$$
T S=c \Delta S+d
$$

for increasing salinity, and

$$
T S=-e \Delta S+f
$$

for decreasing salinity. Where TS is \%activity, $c$ and $e$ are 6.22 and $-6.68 \frac{\text { mactivity }}{\text { ume } x \Delta S}$, respectively, and $d$ and $f$ are 38.01 and $75.15 \%$ activity, respectively.
Eqs. (4) \& (5) were used to vary the percent time oyster larvae swim between a maximum of $83 \%$ and a minimum of $64 \%$ in response to salinity changes. These upper and lower boundaries were derived from laboratory experiments which describe the changes in larval position over time (McCarthy 1989). In these experiments, oyster larvae measuring 70, 130 and $270 \mu \mathrm{m}$ were introduced into $30 \times 0.6 \mathrm{~cm}$ glass cylinders. After a specified period of time, the larval distributions were recorded. The average swimming and sinking speeds for each of the larval sizes were then used to calculate the percentage of time the larvae needed to swim in order to produce the distributions observed in the cylinders. The range of values thus obtained were taken to be the upper and lower boundaries for the percent time swimming profile. A value of $73.5 \%$, which is the average of the upper and lower bounds, was used to initialize the percent time swimming profile.

Using Eqs. (4) \& (5), the percentage of time during which swimming would be observed for a diurnal salinity change between 14 and $24 \mathrm{ppt}$ is shown in Fig. 4. As salinity increases, the larvae increase the percent time swimming at a rate that is proportional to the cumulative salinity change, until reaching $83 \%$. They remain swimming at this percent time until the salinity gradient changes. As salinity is reduced, the percent time swimming decreases until it reaches $6.3 \%$, after which it remains constant. This pattern repeats with the diurnal change in salinity.

The addition of percent time swimming yields a relationship for the effective biological vertical velocity, 
$W_{b i}$, of the form:

$$
W_{b 1}=T S \times S W-(1-T S) \times S R
$$

where TS is percent activity, $S W$ is the swimming rate for a given larval size (Fig. 2) and $S R$ is computed from Eq. (3).

\section{Model implementation}

Larval size is given as length in $\mu \mathrm{m}$, where the length is the maximum anterior-posterior distance (Carriker 1979). Oyster larvae are 55 to $65 \mu \mathrm{m}$ in diameter after fertilization and grow to a setting size of 330 to $335 \mu \mathrm{m}$ (Stafford 1913, Galtsoff 1964). The larval life history was partitioned into 271 size classes, with an interval of $1 \mu \mathrm{m}$, which was sufficient to avoid the smearing of larval cohorts in time.

Eq. (1) was solved in a domain that was $10 \mathrm{~m}$ in depth, with a vertical resolution of $0.5 \mathrm{~m}$, using boundary conditions of no flux of larvae through the surface or the bottom. A single cohort of $100,55 \mu \mathrm{m}$ individuals was introduced into the bottom grid cell on the first day of the simulation, which corresponds to input due to spawning by adult oysters. No larval mortality was included; therefore, all of the 100 larvae released on Day 1 grew to competent setting size. Eq. (1) was solved numerically using a Crank-Nicholson implicit
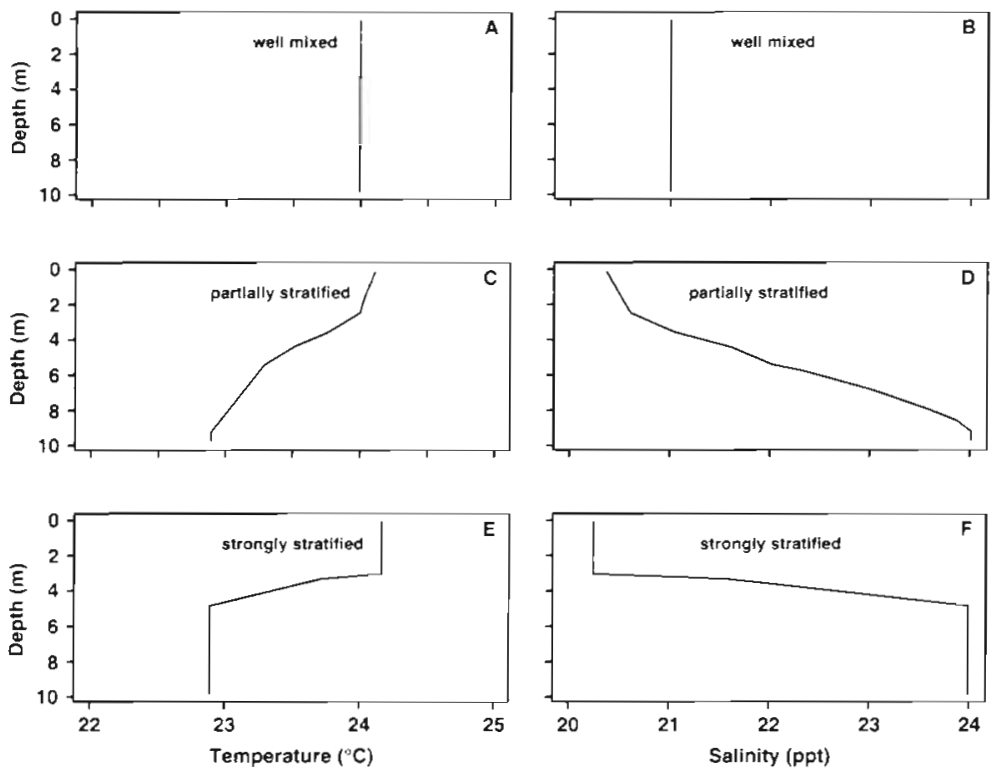

Fig. 5. Temperature and salinity profiles measured in the lower James River (Rennie \& Neilson 1994) that are representative of $(A, B)$ well-mixed and (C, D) partially stratified conditions. (E, F) Strongly stratified conditions were constructed from observed salinity and temperature gradients and the upper and lower temperature and salinity values from the partially stratified conditions. These vertical profiles were used as input for the vertical and timedependent larval model finite difference scheme with a time step of $12 \mathrm{~min}$ which is adequate to resolve the transfer of larvae between size classes.

The temperature and salinity conditions used with the model were chosen to represent a well-mixed water column (Fig. 5A, B), partially stratified conditions (Fig. 5C, D) and a strongly stratified system (Fig. 5E, F). All values were from profiles measured in the lower James River $\left(37^{\circ} 00^{\prime} \mathrm{N}, 76^{\circ} 30^{\prime} \mathrm{W}\right)$ portion of Chesapeake Bay (Rennie \& Neilson 1994). The time series of temperature and salinity were held constant over time, with the exception of the diurnal tide simulation, in which salinity varied between 20.5 and 22.9 ppt. Food and turbidity conditions that are favorable for oyster larval growth (Dekshenieks et al. 1993) were used in order to isolate temperature and salinity effects.

\section{MODEL VERIFICATION}

Before undertaking the Chesapeake Bay simulations, the simulated vertical larval distributions obtained with the oyster larval model were compared with observations. This provides a check on the accuracy of the model and gives a baseline for judging the realism of subsequent simulations. Carriker (1951) provides observations of oyster larval distributions in a $3 \mathrm{~m}$ water column, at 0.0 (surface), 1.0, 1.5 and $2.5 \mathrm{~m}$, that were obtained over a $12 \mathrm{~h}$ period off Landing Creek, Great Bay. New Jersey, USA. Ambient temperature and salinity conditions were also measured. These observations provide the verification data set for the model.

The observations given by Carriker (1951) can be used to obtain the general pattern of larval vertical distribution as a function of larval size (Fig. 6A). The maximum in the distribution of larvae measuring 60 to $150 \mathrm{\mu m}$ is near $1.5 \mathrm{~m}$, with few found near the bottom. Larvae measuring 150 to $220 \mu \mathrm{m}$ were essentially evenly distributed throughout the water column above $1.5 \mathrm{~m}$, but slightly more were located at the surface. Larvae of these sizes have swimming speeds that exceed their sinking speeds and hence should be found in the upper water column. The effect of increased sinking speed is evident in the distributions of larvae measuring 220 to $270 \mu \mathrm{m}$ in length. Larvae of this size are found in the lower portion of the water column. The largest larvae, measuring 270 to $300 \mu \mathrm{m}$, have their maxi- 

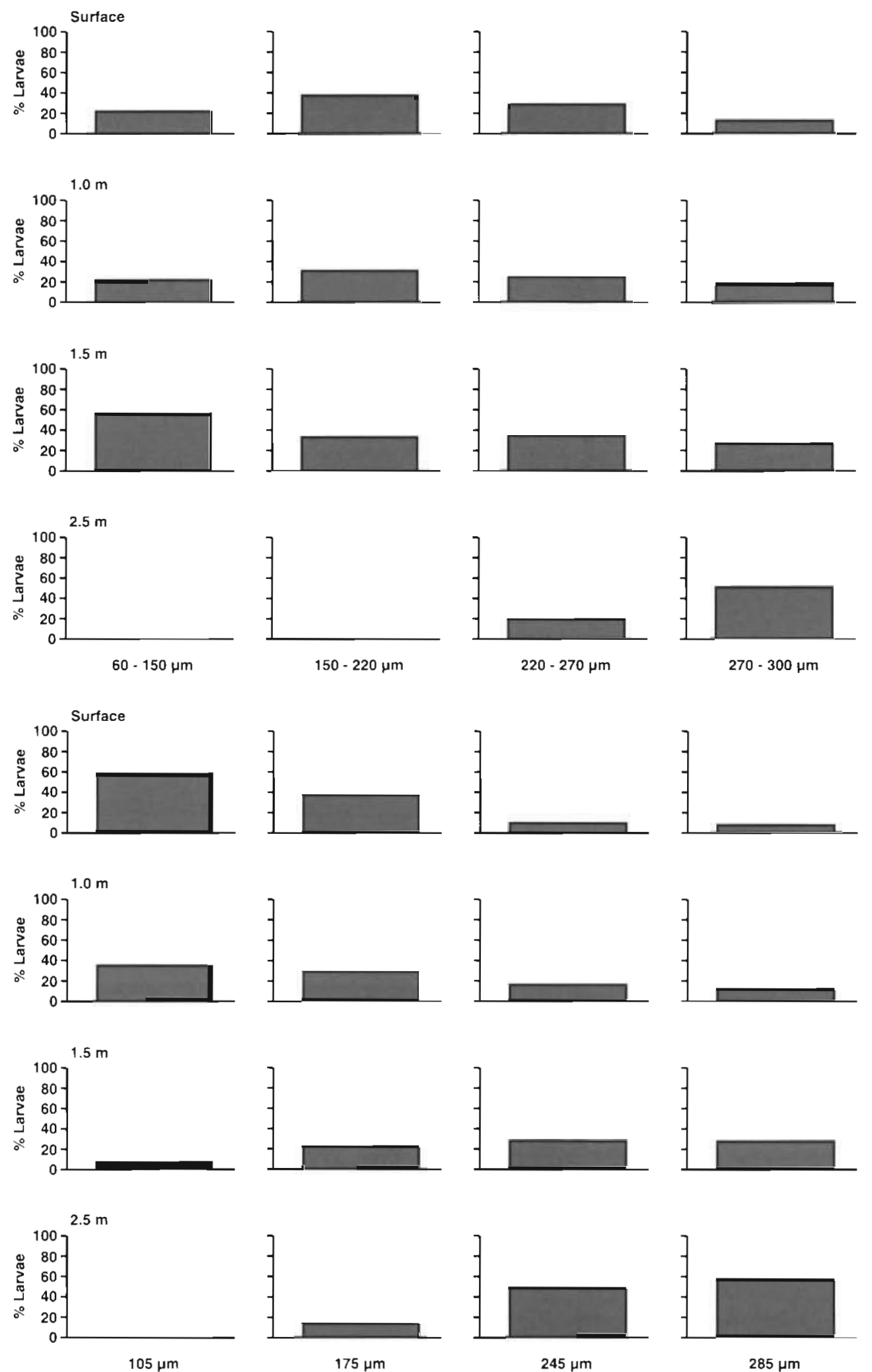

$245 \mu \mathrm{m}$

$285 \mu \mathrm{m}$

Fig. 6. Crassostrea virginica. (A) Vertical distribution of oyster larvae observed by Carriker (1951) in a $3 \mathrm{~m}$ water column over a $12 \mathrm{~h}$ period. Percent larvae at each depth were calculated from the larval abundances. (B) Simulated vertical distribution of oyster larvae obtained when the temperature and salinity time series measured by Carriker (1951) were input to the vertical and time-dependent larval model. Food values were taken to be favorable (2.0 $\mathrm{mg} \mathrm{AFDW}^{-1}$ ) 
mum near the bottom and are not present in the upper regions of the water column in significant densities.

Because Carriker (1951) also recorded local environmental conditions, correlations between vertical larval position and salinity could be obtained. During flood tide (increasing salinity), $95 \%$ of the mature larval stages remained in the water column. On the ebb tide (decreasing salinity) only $35 \%$ of the larvae remained in the water column; the remaining $65 \%$ were found near the bottom (Carriker 1951). The implication of these observations is that oyster larvae reduce their swimming activity during periods of decreasing salinity.

Input of the temperature and salinity measurements recorded by Carriker (1951) to the larval model results in the simulated vertical distributions shown in Fig. 6B. Other environmental conditions used for the simulation are given in Table 2. Larvae measuring 105, 175 , 245 and $285 \mu \mathrm{m}$ represent the average of each of the size groups sampled by Carriker (1951) and are assumed to be representative of these size groupings. To facilitate comparisons, the observed and simulated distributions are expressed as the percent of total individuals.

The simulated vertical distribution of the $105 \mu \mathrm{m}$ larvae shows most of these larvae above $1.5 \mathrm{~m}$, with the largest percent being at the surface. The swimming rates of these earlier stages are greater than sinking rates; therefore the mode, or highest concentration, is located in the upper portion of the water. As the larvae grow in size, their sinking speeds increase. The result of the increased sinking speeds is a more even distribution of larvae throughout the water column, as seen for the $175 \mu \mathrm{m}$ larvae and to a lesser extent for the $245 \mu \mathrm{m}$ larvae. By the time the larvae reach $285 \mu \mathrm{m}$, their sinking speeds have far exceeded their swimming speeds. Over half of the larvae of this size are found near the bottom.

The vertical larval distribution obtained from the model has the same pattern as that obtained from observations. There is a distinct segregation by size of larvae in the water column that results from the balance between sinking and swimming. This basic vertical distribution is further modified by changes in ambient salinity conditions. These patterns are reflected in the simulated vertical larval distributions.

\section{RESULTS}

The simulations presented in the following sections are designed to illustrate the effects of changes in the vertical distribution of temperature and salinity as well as local vertical advection on oyster larvae distribution. The first simulation, however, is the simulated vertical distribution that is obtained for well-mixed (homogeneous) conditions. This provides a reference simulation against which the other simulations can be compared.

\section{Well-mixed water column}

The temperature and salinity profiles measured in the lower James River in September of 1986 (Fig. 5A, $B$ ) are representative of a well-mixed water column. A constant salinity removes the effect of vertical migratory behavior induced by changes in salinity. The vertical larval distributions in the well-mixed case result primarily from the changes in swimming and sinking speeds that occur with larval development, and to a lesser degree, the vertical diffusion in the water column. Food and turbidity values for this simulation (Table 2) are representative of conditions favorable for larval growth (Dekshenieks et al. 1993). No vertical advective effects were included in this simulation (Table 2).

The eggs initially introduced are negatively buoyant and are located near the bottom (Gallager \& Mann 1986) The limited upward movement of the $75 \mu \mathrm{m}$ sized larvae (Fig 7) results from a combination of low

Table 2. Summary of environmental conditions used for the simulations

\begin{tabular}{|c|c|c|c|c|c|c|c|c|}
\hline Simulation & $\begin{array}{c}\text { Water } \\
\text { depth } \\
\text { (m) }\end{array}$ & $\begin{array}{c}\text { Temperature } \\
\left({ }^{\circ} \mathrm{C}\right)\end{array}$ & $\begin{array}{l}\text { Salinity } \\
\text { (ppt) }\end{array}$ & $\begin{array}{c}\text { Food } \\
\left(m g \text { AFDW }^{-1}\right)\end{array}$ & $\begin{array}{c}\text { Turbidity } \\
\left(\mathrm{g}^{-1}\right)\end{array}$ & $\begin{array}{l}\text { Vertical } \\
\text { velocity } \\
\left(\mathrm{m} \mathrm{d}^{-1}\right)\end{array}$ & $\begin{array}{l}\text { Vertical } \\
\text { diffusion } \\
\left(\mathrm{m}^{2} \mathrm{~d}^{-1}\right)\end{array}$ & $\begin{array}{l}\text { Fig. no. } \\
\text { (this study) }\end{array}$ \\
\hline Verification $^{d}$ & 3 & $24.2-25.3$ & $22.0-24.0$ & 2.0 & 0.0 & 0.0 & 30 & $6 \mathrm{~B}$ \\
\hline Well-mixed ${ }^{b}$ & 10 & 24.0 & 21.0 & 2.0 & 0.0 & 0.0 & 30 & 7 \\
\hline Partially stratified ${ }^{b}$ & 10 & $22.9-24.0$ & $20.4-24.2$ & 2.0 & 0.0 & 0.0 & 30 & 8 \\
\hline Strongly stratified ${ }^{b}$ & 10 & $22.9-24.0$ & $20.4-24.2$ & 2.0 & 0.0 & 0.0 & 30 & 9 \\
\hline Diurnal tide & 10 & 24.0 & $20.5-22.9$ & 2.0 & 0.0 & 0.0 & 30 & 10 \\
\hline Upwelling velocity & 10 & 24.0 & 21.0 & 2.0 & 0.0 & $+10.0^{\mathrm{d}}$ & 30 & 11 \\
\hline Downwelling velocity & 10 & 24.0 & 21.0 & 2.0 & 0.0 & $-10.0^{d}$ & 30 & 12 \\
\hline
\end{tabular}




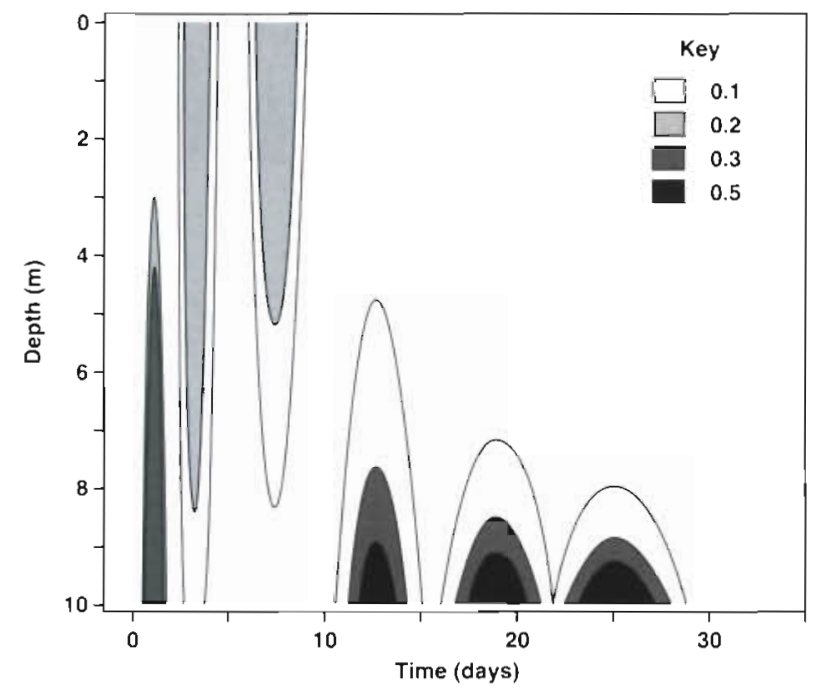

Fig. 7 Crassostrea virginica. Simulated vertical and time distribution of 6 larval sizes $(75,94,150,200,250,300 \mu \mathrm{m})$ obtained for well-mixed temperature and salinity conditions. Other conditions are given in Table 2. Contours are the number of larvae per $0.5 \mathrm{~m}$. Note that the contour interval is variable and that the 0.4 contour has been eliminated to enhance contrast

swimming speeds and vertical diffusion. At a temperature of $24^{\circ} \mathrm{C}$, development through the smaller sizes is rapid. At this temperature, larvae grow to $94 \mu \mathrm{m}$ in $3 \mathrm{~d}$. Larvae measuring $94 \mu \mathrm{m}$ have moderate swimming speeds and are spread almost uniformly through the water column (Fig. 7). After about 7 d, the larvae reach a size of $150 \mu \mathrm{m}$. At this time, their swimming speeds have increased considerably and still remain greater than larval sinking speeds. Larvae measuring $150 \mu \mathrm{m}$ are located in the upper regions of the water column. By the time the larvae have reached $200 \mu \mathrm{m}$, sinking speeds exceed swimming speeds, and the $200 \mu \mathrm{m}$ larvae shift from the upper to the lower region of the water column (Fig. 7). As the larvae continue to increase in size, their sinking speeds increase more rapidly than their swimming speeds. Consequently, the more mature larvae are found in increasing numbers near the bottom.

\section{Partially stratified water column}

The temperature and salinity conditions measured in the lower James River in April of 1985 (Fig. 5C, D) provided environmental conditions that are representative of a partially stratified estuary. Warmer, less saline surface water overlays cooler, higher salinity hottnm water, with gradual gradients of both salinity and temperature between the surface and the bottom. Other environmental conditions are as given in Table 2

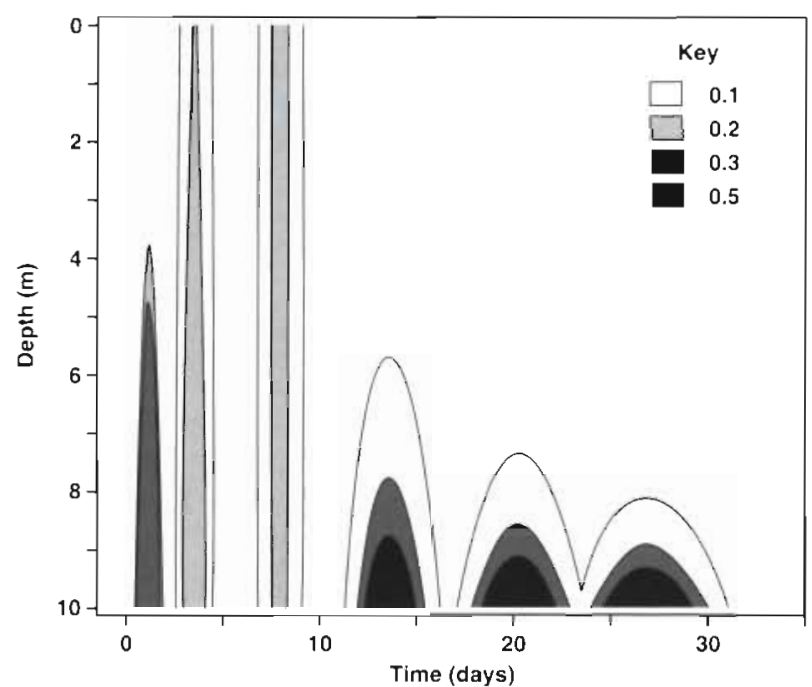

Fig. 8. Crassostrea virginica. Simulated vertical and time distribution of 6 larval sizes $(75,94,150,200,250,300 \mu \mathrm{m})$ obtained for temperature and salinity conditions that are representative of a partially stratified estuary. Other conditions are given in Table 2. Contours are the number of larvae per $0.5 \mathrm{~m}$. Note that the contour interval is variable and that the 0.4 contour has been eliminated to enhance contrast

The gradients in temperature and salinity have the most effect on the vertical distribution of the 94 and $150 \mu \mathrm{m}$ larvae (Fig. 8). The maximum density of 94 and $150 \mathrm{~mm}$ larvae is shifted lower in the water column. This change in distribution results from the interaction of 2 larval responses. First, larvae encountering decreases in salinity, decrease the amount of time spent swimming. This behaviar shifts the 94 and $150 \mu \mathrm{m}$ larvae to a lower position in the water column. Second, larval swimming speed is a function of temperature, with larvae swimming more slowly at cooler temperatures. Slower swimming speeds prevent the larvae from moving upwards. The effects of lower temperatures and upwardly decreasing salinities are also evident in the vertical distributions of the more mature larval stages, which do not extend as far upward into the water column as seen for well mixed conditions (Fig. 8 vs Fig. 7).

\section{Strongly stratified water column}

The surface and bottom temperature and salinity values from the partially stratified case were used with a sharp gradient between 3 and $5 \mathrm{~m}$, to construct vertical profiles that represent a strongly stratified condition (Fig $5 \mathrm{E}$. F). The vertical larval distributions produced by these vertical profiles (Fig. 9) differ considerably from those obtained for homogeneous conditions (Fig. 7). When the water column is strongly 


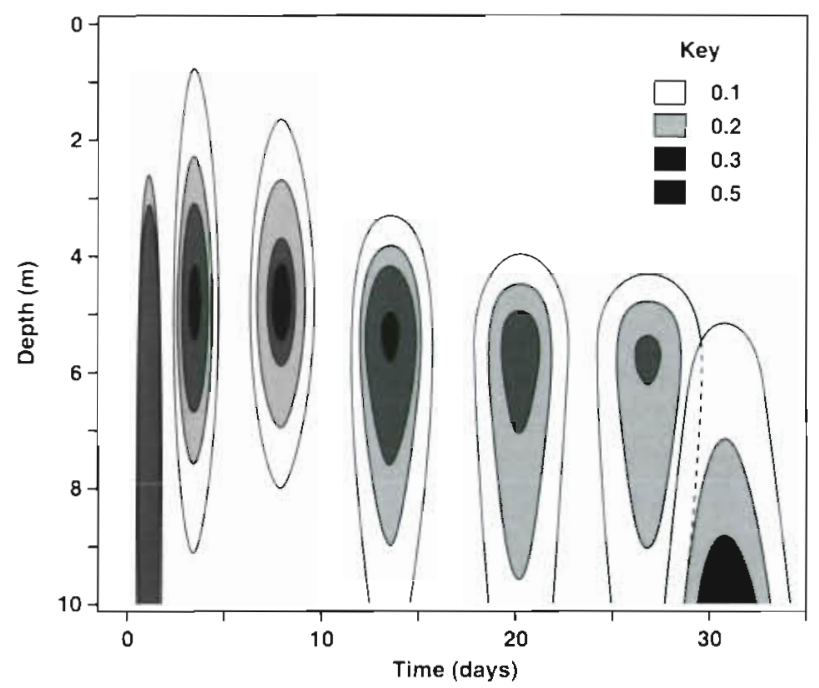

Fig. 9. Crassostrea virginica. Simulàied ventical and time distribution of 7 larval sizes $(75,94,150,200,250,300,334 \mu \mathrm{m})$ obtained for temperature and salinity conditions that are representative of a strongly stratified estuary. Other conditions are given in Table 2 . Contours are the number of larvae per $0.5 \mathrm{~m}$. Note that the contour interval is variable and that the 0.4 contour has been eliminated to enhance contrast

stratified, the highest concentration of all larval stages is centered at or just below the salinity and temperature gradient.

The simulated vertical distribution of larvae measuring 94 and $150 \mu \mathrm{m}$ shows maximum concentrations centered in the region of the steepest gradient change at 3 and $5 \mathrm{~m}$ (Fig. 9). Larvae directly below the region of gradient change respond to the increasing salinity by increasing their activity. Those directly above the gradient respond to decreasing salinity by decreasing their activity. Thus, the upper and lower bounds on the maximum concentration of the 94 and $150 \mu \mathrm{m}$ larvae are determined by the larval response to the steep salinity gradient.

The maximum concentrations of the more mature larvae are located below the gradient, and are increasingly deeper for the larger larval sizes (Fig. 9). The higher sinking velocities of the older larvae prevent them from moving into the upper water column.

The strongly stratified simulation was run with a diffusion rate which was constant with depth. In regions of strong stratification the diffusion rate varies with depth, reaching a minimum within the region of stratification. For this reason, an additional simulation was run to determine the effect of a vertically varying diffusion rate on larval distribution. The vertical diffusion profile was obtained by using a relationship between diffusion and salinity change. The simulated vertical larval profiles obtained with a depth-varying diffusion coefficient showed only slight differences for larvae

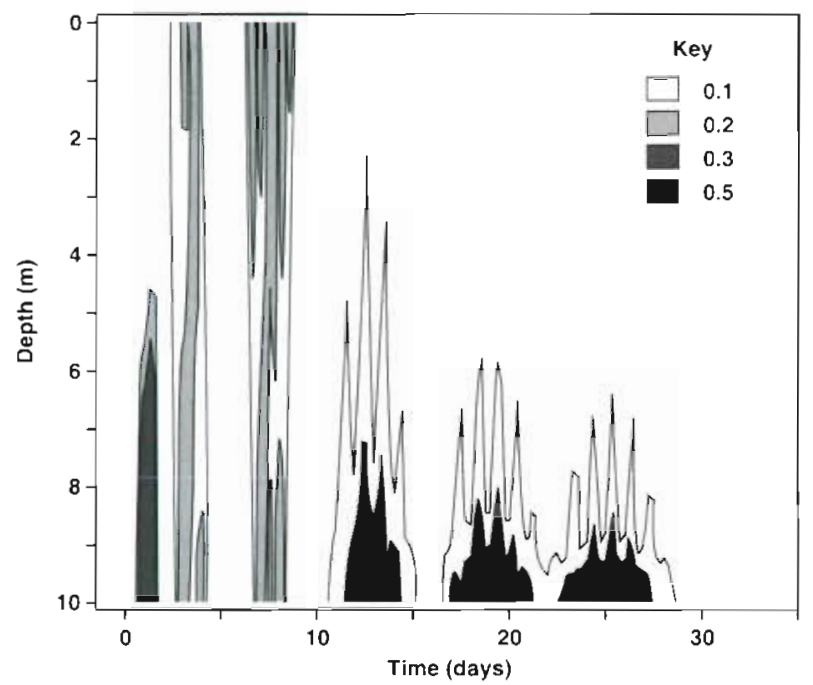

Fig. 1.0. Crassostrea virginica. Simulated vertical and time distribution of 6 larval sizes $(75,94,150,200,250,300 \mu \mathrm{m})$ obtained for diurnally varying salinity conditions. Other conditions are given in Table 2. Contours are the number of larvae per $0.5 \mathrm{~m}$. Note that the contour interval is variable and that the 0.4 contour has been eliminated to enhance contrast

measuring 94 and $150 \mu \mathrm{m}$. These smaller larvae were more concentrated around the region of stratification than was found for the constant diffusion simulation. The differences in larval distribution are not significant because larval swimming and sinking speeds are great enough to overcome the effects of diffusion.

\section{Diurnal changes}

Many estuarine systems experience increases and decreases in salinity over $24 \mathrm{~h}$ which arise from diurnal tidal effects. The influence of such a salinity change on the vertical distribution of oyster larvae was investigated by imposing a diumally varying salinity, recorded in the lower James River by Wood \& Hargis (1971), which ranged from 20.5 to $22.9 \mathrm{ppt}$. These salinity values are within the range of conditions favorable for larval growth (Dekshenieks et al. 1993). Other conditions are as specified in Table 2.

The simulated vertical larval distributions show larvae rising up into the water column as salinity increases on the flood tide and moving downward in response to decreasing salinity on the ebb tide (Fig 10). Salinity effects on swimming results in larvae larger than $150 \mu \mathrm{m}$ being dispersed over a greater portion of the water column relative to the well-mixed case. Hence, the total distance over which these larvae move is greater

The diurnal increases and decreases in salinity alter the time the larvae spend swimming. This has the most 


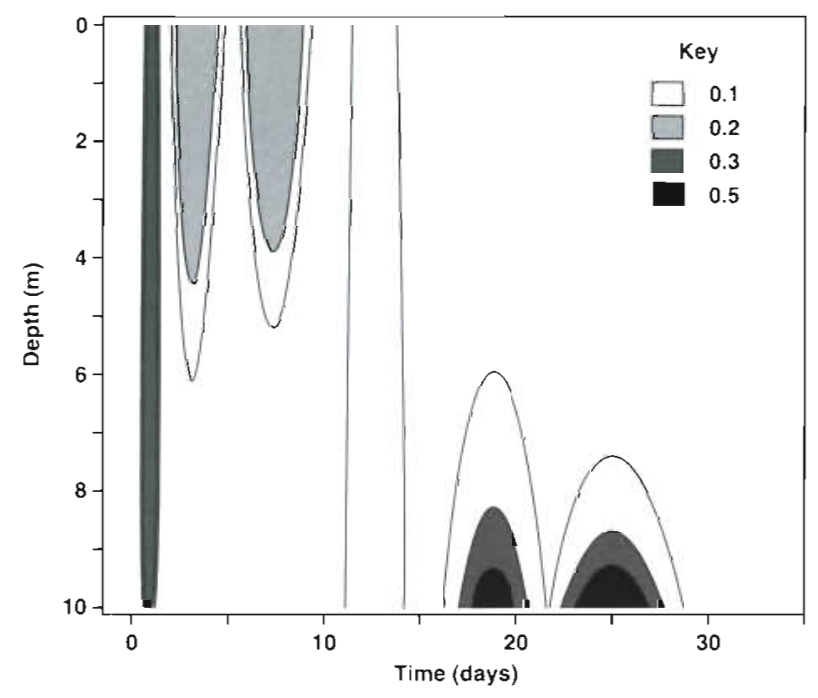

Fig. 11. Crassostrea virginica. Simulated vertical and time distribution of 6 larval sizes $(75,94,150,200,250,300 \mu \mathrm{m})$ obtained for an upwelling velocity of $10 \mathrm{~m} \mathrm{~d}^{-1}$ Other conditions are given in Table 2. Contours are the number of larvae per $0.5 \mathrm{~m}$. Note that the contour interval is variable and that

the 0.4 contour has been eliminated to enhance contrast

effect on the intermediate-sized larvae, which have swimming rates greater than their sinking rates. As a result, the 94 and $150 \mu \mathrm{m}$ larvae are split into 2 modes; one near the bottom and the other near the surface. The diurnal variations in salinity also cause the largersized larvae to periodically move higher into the water column (Fig. 10). The vertical distance over which these larvae are dispersed changes by as much as 5 , 2.5 and $2 \mathrm{~m}$ for the 200, 250 and $300 \mu \mathrm{m}$-sized larvae, respectively, relative to the well-mixed case.

\section{Upwelling and downwelling velocity effects}

Upwelling and downwelling velocities are often produced in frontal regions and serve as a means for vertically transporting oyster larvae. The vertical advective velocities used in these simulations (Table 2) are representative of those that may be encountered in divergent or convergent regions (Pond \& Pickard 1983). The remaining environmental conditions were set to levels favorable for larval development (Table 2).

An upwelling velocity of $10 \mathrm{~m} \mathrm{~d}^{-1}$ results in the upward displacement of all larval sizes relative to the well-mixed case (Fig. 11). The $75 \mu \mathrm{m}$ larvae are distributed throughout the water column, while the distri-

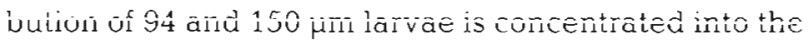
upper $5 \mathrm{~m}$ of the water column. Larvae measuring $200 \mu \mathrm{m}$ are distributed throughout the entire water column. The upwelling velocity has a relatively smaller

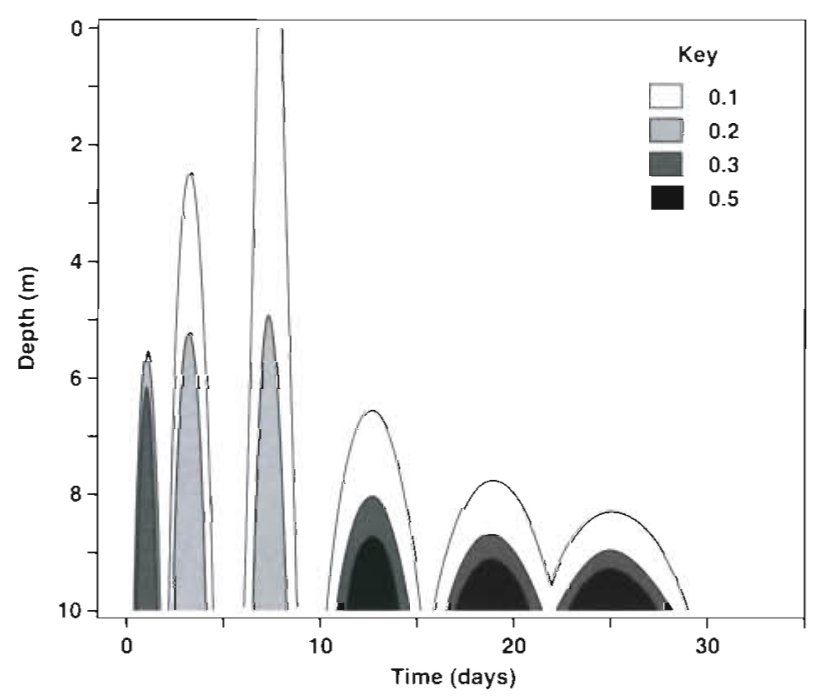

Fig. 12. Crassostrea virginica. Simulated vertical and time distribution of 6 larval sizes $(75,94,150,200,250,300 \mu \mathrm{m})$ obtained for a downwelling velocity of $10 \mathrm{~m} \mathrm{~d}^{-1}$ Other conditions are given in Table 2. Contours are the number of larvae per $0.5 \mathrm{~m}$. Note that the contour interval is variable and that

the 0.4 contour has been eliminated to enhance contrast

effect on the 250 and $300 \mu \mathrm{m}$ larvae, which have sinking speeds sufficient to counteract upwelling velocities to some degree.

A downwelling velocity of $10 \mathrm{~m} \mathrm{~d}^{-1}$ reduces the amount of upward vertical dispersion for all sizes of larvae relative to that seen in the well-mixed case (Fig. 12). The maximum concentration of all larval sizes is shifted downward in the water column. The most dramatic differences in larval distribution occur for larvae measuring 94 and $150 \mu \mathrm{m}$, whose swimming speeds are not sufficient to counteract the effects of the downwelling velocity. Smaller differences between the downwelling and well-mixed cases occur in the simulated distributions for the 200,250 and $300 \mu \mathrm{m}$-sized larvae (Fig. 12).

\section{DISCUSSION}

\section{Stratification}

The role of vertical gradients in temperature and salinity in affecting the vertical distribution of oyster larvae of 150 and $200 \mu \mathrm{m}$ in size is summarized in Fig. 13. Larvae of these sizes show the most response to changes in environmental gradients. For well-mixed conditions, the $150 \mu \mathrm{m}$ larrae are found throughout the water column, except near the bottom. The larger larvae are found in the lower portion of the water column. For these conditions vertical distributions are essen- 


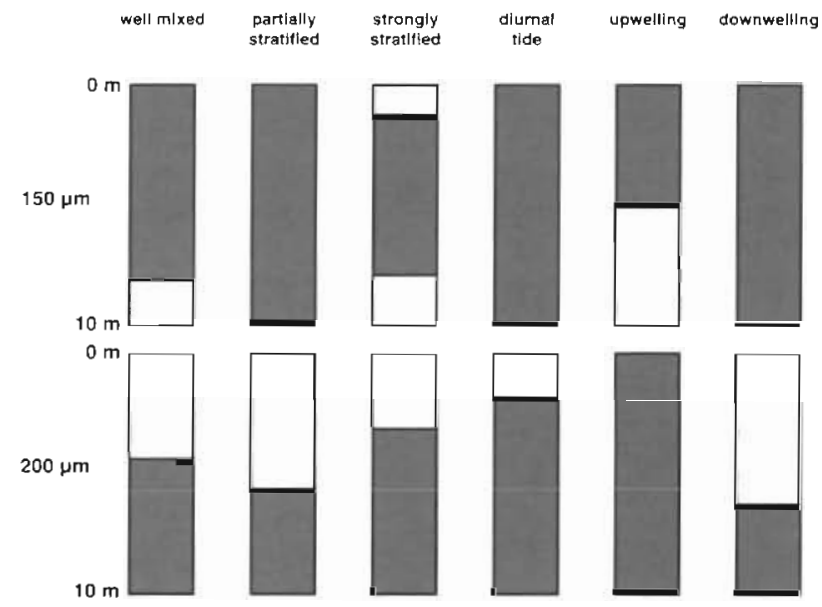

Fig. 13. Crassostrea virginica. Summary of the simulated vertical distribution for ovster larvae measuring 150 and $200 \mu \mathrm{m}$. Shaded region indicates the portion of the water column in which larvae of these sizes were found

tially determined by the relative contribution of swimming and sinking. The presence of weak stratification alters the distribution of the smaller larvae, but has little effect on the larger larvae. The presence of strong stratification has a greater effect on vertical larval distributions.

The simulated vertical larval distributions obtained for the strongly stratified conditions show oyster larvae of all sizes concentrating at or directly below the region of the sharp salinity gradient. These simulated distributions arise solely from the larval response to vertical changes in temperature and salinity. Analysis of the model processes show that the mechanism concentrating larvae in regions of sharp discontinuities is primarily the behavioral response to salinity gradients. Temperature is a secondary effect. A separate study of the responses of 3 bivalves to salinity changes showed that larvae of all 3, independent of developmental stage, had highest concentrations in regions of highest salinity discontinuity (Mann 1991). Hence, the observed tendency for larvae to concentrate in pycnocline regions may be primarily a behavioral response.

\section{Salinity}

Salinity has the greatest effect on the vertical position of oyster larvae, especially for the intermediatesized larvae. At an average temperature of $24^{\circ} \mathrm{C}$ the swimming and sinking speeds of mid-sized larvae are about equivalent. Hence, larvae of these sizes are extremely sensitive to small increases or decreases in salinity which cause the larvae to migrate upwards or downwards, respectively. Salinity has less of an effect on the more mature larvae whose sinking speeds, which exceed any swimming speeds, maintain the mode of the more mature population on or near the bottom of the water column.

When a diurnal salinity is imposed, considerable structure in the vertical larval distribution results. The larger larvae are found higher in the water column (Fig. 13) and hence the potential for increased dispersal of these size classes is increased. Also, the vertical structure that results from the varying salinity can potentially lead to patchiness in the distribution of the oyster larvae. This may be a mechanism that separates a discrete spawn into mesoscale patches.

The ability to migrate in response to environmental stimuli could be a contributing factor that allows oyster larvae to reach a suitable substrate at the time of metamorphosis. Wood \& Hargis (1971) compared the transport of oyster larvae and passive coal particles in the James River Estuary of the Chesapeake Bay and found that the distribution of the two were different. Their conclusion was that the oyster larvae were not being transported passively, but rather by a process of selective swimming which contributed to their up-river movement. They suggested that the migratory capability of these larvae, sinking when the salinity decreases during the ebb tide and swimming upward when salinities increase on the flood tide, may serve as the primary mechanism leading to the transport of larvae back up-estuary often beyond spawning grounds (Wood \& Hargis 1971).

\section{Circulation effects}

The physical structures, such as upwelling and downwelling regions associated with fronts, that are found in estuaries affect the vertical distribution of oyster larvae. The simulations for upwelling and downwelling conditions show that variations in vertical velocity can significantly alter the vertical location of oyster larvae. In these simulations the effects of the physical environment overwhelm the behavioral response and the larvae are transported essentially as passive particles. For upwelling conditions intermediate-sized larvae are found in the upper water column or are dispersed throughout the water column (Fig. 13). Downwelling velocities tend to concentrate larvae in the lower portion of the water column. Hence, the potential for dispersal may be greater for upwelling conditions since the larvae are more frequently in the water column.

Mann (1988) studied the role of a frontal system in the James River estuary of the Chesapeake Bay in controlling the distribution of oyster larvae. The frontal region, which developed during the early flood tide, 
had associated with it downwelling water velocities which passively transported larvae downwards. A second study of larval advection (Jacobsen et al. 1990) addressed questions relating to recruitment of oyster larvae in the Delaware Bay, USA. This study combined 2 field studies with a numerical modeling study of the Delaware Bay. Simulated particle trajectories were calculated using 3 different simulated larval migration schemes. The results of the study suggested that frontal transport, which displaces larvae into the lower layers of the water column, is a key factor in the dispersion of oyster larvae (Jacobsen et al. 1990).

Similar patterns were seen in the simulated vertical larval distributions; downwelling conditions tend to concentrate larvae of all sizes in the lower portion of the water column. Thus, regions of downwelling and convergence, even if transient in nature, could displace larvae downwards and prevent then from reaching suitable setting grounds. However, it is also possible that the larvae could use downwelling velocities for transport to suitable reef areas.

In the classic 2-layered estuarine circulation (Pritchard 1952) there is a net seaward flow in the upper water column and a net inward flow of water in the lower water column. The earlier larval stages that have swimming speeds in excess of their sinking speeds are more frequently in the upper part of the water column where they could potentially be transported out of the estuary. Under sub-optimal environmental conditions, such as low salinity, low temperature or low food concentration, the total planktonic time and subsequently the amount of time larvae remain in the size ranges corresponding to the earlier stages of larvae is extended (Dekshenieks et al. 1993). If these early stages were incapable of vertically adjusting their position in the water column, under conditions unfavorable for larval growth, the probability that larvae in the upper water column would be flushed from the estuary is high.

Acknowledgements. This research was supported by the US Army Corps of Engineers, Galveston District office grant DACW64-91-C-0040 to Texas A\&M University and Old Dominion University. Computer facilities and resources were provided by the Commonwealth Center for Coastal Physical Oceanography.

\section{LITERATURE CITED}

Baker P (1991) Effect of neutral red stain on settlement ability of oyster pediveligers, Crassostrea virginica. J Shellfish Res 10:455-456

Boicourt WC (1982) Estuarine larval retention mechanism on two scales. In: Kennedy VS (ed) Estuarine comparisons. Academic Press, New York, p 445-457

Carriker MR (1951) Ecological observations on the distribution of oyster larvae in New Jersey estuaries. Ecol Monogr 21:19-38
Carriker MR (1979) Ultrastructural morphogenesis of prodissoconch and early dissoconch valves of the oyster Crassostrea virginica. Proc Natl Shellfish Ass 69:103-128

Crisp DJ (1976) Settlement responses in marine organisms. In: Newell RC (ed) Adaptation to environment. Essays on the physiology of marine animals. Butterworths, London, $\mathrm{p}$ $83-124$

Davis HC (1958) Survival and growth of clam and oyster larvae at different salinities. Biol Bull Mar Biol Lab Woods Hole 114:296-307

Davis HC (1960) Effects of turbidity-producing materials in sea water on eggs and larvae of the clam (Venus (Mercenaria) mercenaria). Biol Bull Mar Biol Lab Woods Hole $118: 48-54$

Davis HC, Calabrese A (1964) Combined effects of temperature and salinity on the development of eggs and growth of larvae of Mercenaria mercenaria and Crassostrea virginica. US Fish Wildl Serv Fish Bull 63:643-655

Dekshenieks MM, Hofmann EE, Powell EN (1993) Environmental effects on the growth and development of Eastern oyster, Crassostrea virginica (Gmelin, 1791), larvae: a modeling study. J Shellfish Res 12:241-254

Gallager SM, Mann R (1986) Growth and survival of larvae of Mercenaria mercenaria (L.) and Crassostrea virginica (Gmelin) relative to broodstock conditioning and lipid content of eggs. Aquaculture 56:105-121

Galtsoff PS (1964) The American oyster Crassostrea virginica (Gmelin). US Fish Wildl Serv Fish Bull 64:1-480

Haskin $\mathrm{HH}$ (1964) The distribution of oyster larvae. In: Marshall N, Jeffries HP, Napora TA, Sieburth JM (eds) Symposium on experimental marine ecology, Graduate School of Oceanography, University of Rhode lsland, Occ Publ 2: $76-80$

Hidu HH, Haskin H (1978) Swimming speeds of oyster larvae Crassostrea virginica in different salinities and temperatures. Estuaries 1:252-255

Hofmann EE, Capella JE, Ross RM, Quetin LB (1992) Models of the early life history of Euphausia superba-Part I. Time and temperature dependence during the descentascent cycle. Deep Sea Res 39:1177-1200

Hofmann EE, Lascara CM (in press) A review of predictive modeling for coastal marine ecosystems. In: Mooers C (ed) Coastal ocean prediction. Coastal and Estuarine Sciences, American Geophysical Union, Washington, DC

Huntington KM, Miller DC (1989) Effects of suspended sediment, hypoxia and hyperoxia on larval Mercenaria mercenaria (Linnaeus, 1758). J Shellfish Res 8:37-42

Jacobsen TR, Milutinovic JD, Miller JR (1990) Observational and model studies of physical processes affecting benthic Larval recruitment in Delaware Bay. J Geophys Res 95: $20,331-20,345$

Kennedy VS, Van Heukelem W (1986) Responses to environmental factors by larval oysters Crassostrea virginica. Am Malac Bull 4:101

Korringa P (1952) Recent advances in oyster biology. Q Rev Biol 27:266-308, 339-365

Kunkle DE (1957) The vertical distribution of oyster larvae in Delaware Bay. Proc Natl Shellfish Ass 48:90-91

Mann R (1986) Sampling of bivalve larvae. In: Jamieson GS, Bourne N (eds) North Pacific workshop on stock assessment and management of invertebrates. Can Spec Publ Fish Aquat Sci 92:107-116

Mann R (1988) Distribution of bivalve larvae at a frontal system in the James River, Virginia. Mar Ecol Prog Ser 50:29-44

Mann R (1991) Swimming rate and responses of larvae of three mactrid bivalves to salinity discontinuities. Mar Ecol Prog Ser 68:257-269 
Mann R, Rainer JS (1990) Effect of oxygen tension on swimming rate of Crassostrea virginica larvae (Gmelin, 1791). $J$ Shellfish Res 9:323-327

McCarthy KJ (1989) Influence of salinity on swimming behavior of larvae Crassostrea virginica. Masters Thesis. Virginia Institute of Marine Science, Gloucester, VA

Nelson TC (1954) Observations of the behavior and distribution of oyster larvae. Proc Natl Shellfish Ass 45: $23-28$

Pond S, Pickard GL (1983) Introductory dynamical oceanography. Pergamon Press, Oxford

Pritchard DW (1952) Distribution of oyster larvae in relation to hydrographic conditions. Proc Gulf Caribb Fish Inst 1952: $123-132$

Rennie S, Neilson B (1994) Chesapeake Bay Atlas: US EPA Monitoring Program Water Quality Data 1984-1991 CD-ROM, Virginia Institute of Marine Science Data Report No 55, April 1994, Virginia Institute of Marine Sclence, Gloucester, VA

This article was presented by D. C. Schneider /Senior Editorial Advisor), St. Johns, Newfoundland, Canada
Rhodes EW, Landers WS (1973) Growth of oyster larvae, Cras sostrea virgnica, of various sizes in different concentrations of the chrysophyte, Isochrysis galbana. Proc Nat] Shellfish Ass 63:53-59

Rothlisberg PC (1983) Modeling the advection of vertically migrating shrimp larvae. J Mar Res 41:51.1-538

Stafford J (1913) The Canadian oyster, its development, environment and culture. The Mortimer Co, Ltd, Ottawa

Verwey J. (1966) The role of some external factors in the vertical migration of manne animals. Neth $J$ Sea Res 3 245-266

Wood L, Hargis WJ (1971) Transport of bivalve larvae in a tidal estuary. In: Crisp DJ (ed) Proceedings of the Fourth European Marine Biology Symposium, Bangor, 1969. Cambridge University Press, Cambridge, p 29-44

Wroblewski JS (1982) Interaction of currents and vertical migration in maintaining Calanus marshallae in the Oregon upwelling zone-a simulation. Deep Sea Res 29 . $665-686$

Manuscript first received: September 20, 1994

Revised version accepted: December 8, 1995 